\title{
Pancasila Education Policy in Government Regulation Number 57 of 2021 concerning National Education Standards
}

\author{
Bramastia $^{1}$, Arief Sadjiarto ${ }^{2}$ \\ Program Studi Magister Pendidikan Sains Pascasarjana Fakultas Keguruan dan IImu \\ Pendidikan Universitas Sebelas Maret Surakarta', Program Studi Pendidikan Ekonomi \\ Fakultas Keguruan dan IImu Pendidikan Universitas Kristen Satya Wacana Salatiga ${ }^{2}$ \\ bramastia@staff.uns.ac.id ${ }^{1}$, arief.sadjiarto@uksw.edu²
}

\section{Article History}

accepted 10/04/2021

published 20/04/2021

\begin{abstract}
The Pancasila education policy in Government Regulation Number 57 of 2021 concerning National Education Standards (SNP) must be revised. Pancasila must be a mandatory content in the Indonesian education system. Pancasila education in Indonesia in the reform era through the revision of Government Regulation Number 57 of 2021 concerning SNP cannot be separated from the national politics behind it.Educational reform through the revision of Government Regulation Number 57 of 2021 concerning SNP, in turn brings changes to the paradigmatic aspects of the study and learning of Pancasila education in Indonesia from the aspect of national education standardization. The objective of the Merdeka Belajar program is the profile of Pancasila students as an educational transformation. The introduction of Pancasila in the understanding and application of Pancasila is the main pillar of the transformation of Indonesian education which does not depend on a change of regime in power.
\end{abstract}

Keywords: education policy, Pancasila, PP 57 Tahun 2021

\begin{abstract}
Abstrak
Kebijakan pendidikan Pancasila dalam Peraturan Pemerintah Nomor 57 Tahun 2021 tentang Standar Nasional Pendidikan (SNP) harus direvisi. Pancasila harus menjadi muatan wajib di dalam sistem pendidikan Indonesia. Pendidikan Pancasila di Indonesia pada era reformasi melalui revisi PP Nomor 57 Tahun 2021 tentang SNP tidak dapat dilepaskan dari politik nasional yang melatarbelakanginya. Reformasi pendidikan melalui revisi PP Nomor 57 Tahun 2021 tentang SNP, pada gilirannya membawa perubahan pada aspek paradigmatik kajian dan pembelajaran pendidikan Pancasila di Indonesia dari aspek standardisasi nasional pendidikan. Tujuan program Merdeka Belajar yaitu profil pelajar Pancasila sebagai transformasi pendidikan. Pengenalan Pancasila dalam pemahaman dan aplikasi Pancasila menjadi pilar utama daripada transformasi pendidikan Indonesia yang tidak tergantung kepada pergantian rezim kekuasaan.

Kata kunci: kebijakan pendidikan, Pancasila, PP 57 Tahun 2021
\end{abstract}

Social, Humanities, and Education Studies (SHEs): Conference Series https://jurnal.uns.ac.id/shes 


\section{PENDAHULUAN}

Dalam dunia pendidikan, kelahiran Undang-Undang RI No. 20 Tahun 2003 tentang Sistem Pendidikan Nasional (Sisdiknas) membawa dampak besar dalam reformasi pendidikan nasional sendiri. Di bidang pendidikan kewarganegaraan, dan umumnya dalam kurikulum pendidikan formal di sekolah dasar hingga menengah, reformasi tidak hanya terbatas dalam substansi kajian, metode, dan sistem penilaian. Pembaharuan pendidikan telah bergeser kepada paradigma pembentukan warga negara demokratis sebagaimana idealitas universal daripada sebuah misi pendidikan itu sendiri.

Sebaliknya, studi tentang kebijakan pendidikan tidak dapat dilepaskan dari pengkajian politik pendidikan itu sendiri. Wong (1995:21) menyebutkan bahwa politik pendidikan sebagai sebuah lapangan kajian keilmuan memiliki akar intelektualnya dalam ilmu politik. Dengan demikian, perhatian utama politik pendidikan akan mempergunakan pula pada domain-domain ilmu politik seperti: kekuasaan (power), pengaruh (influence), konflik (pertikaian), dan alokasi nilai-nilai otoritatif (authoritative allocation of values).

Pasca keluarnya Peraturan Pemerintah (PP) Nomor 57 Tahun 2021 tentang Standar Nasional Pendidikanmenuai polemik dan kritik dari berbagai kalangan.Keberadaan PP Nomor 57 Tahun 2021 tentang Standar Nasional Pendidikan telah ditandatangani Presiden Joko Widodo dan diundangkan oleh Menkumham menimbulkan polemik dan kegaduhan dari aturan yang ada.

Implikasi menghilangkan Pancasila dan Bahasa Indonesia sebagai mata kuliah wajib di perguruan tinggi tentu tidak sesuai dengan ketentuan yang diatur dalam Pasal 35 ayat (3) UU No 12 Tahun 2012 tentang Perguruan Tinggi. Berbagai kritik muncul karena hilangnya kata Pancasila dan Bahasa Indonesia sebagai Mata Kuliah Wajib untuk Perguruan Tinggi dalam PP Nomor 57 Tahun 2021. Hilangnya Pancasila dan Bahasa Indonesia sebagai mata kuliah wajib sangat meresahkan di tengah pemerintah gencar mengajak rakyat melaksanakan Pancasila, memerangi terorisme dan radikalisme.

Untuk itu, pentingnya melakukan evaluasi menyeluruh dan merevisi atas PP Nomor 57 tahun 2021 agar kebijakan atau proses legislasi yang dilakukan pemerintah tidak lagi dilakukan secara tergesa-gesa, mengedepankan prinsip kehati-hatian dan harus lebih profesional.Sehingga perlu dilakukan evaluasi untuk memastikan bahwa kesalahan tidak terjadi lagi dan siapapun yang bertanggung jawab atas kesalahan harus diberi sanksi.

Bagaimanapun, persoalan kesalahan dalam PP Nomor 57 Tahun 2021 tidak hanya mispersepsi sebagaimana disampaikan Mendikbud, tetapi adanya proses penyiapan suatu PP yang isinya tidak sesuai dengan Undang-Undang kemudian dibiarkan sampai kepada meja Presiden dan bahkan sudah ditandatangani Presiden serta diundangkan Menkumham.Artinya, bahwa kesalahan PP 57 Tahun 2021 bisa menjadi bukti tidak dikoreksi dengan serius terhadap proses pembuatan relislasi dan kejadian ini menjadi teladan buruk serta pembelajaran negatif khusus bagi dunia Pendidikan.

Kejadian ini menjadi pelajaran bagi pemerintah, dan segera mengoreksi dengan cara yang legal, yaitu PP secara resmi segera dicabut oleh Presiden dan dilakukan evaluasi secara menyeluruh.Sehingga setelah dipastikan tidak lagi bermasalah, maka Presiden tinggal mengeluarkan PP baru yang mewajibkan atas pelajaran Pancasila dan Bahasa Indonesia beserta pengaturan teknisnya, sebagaimana diatur dalam UU Perguruan Tinggi, UU Sisdiknas dan juga UUDasar Negara 1945.

Paradigma baru pendidikan Pancasila harus fokuskan diri dalam upaya membentuk peserta didik sebagai masyarakat kewargaan (civil society) dengan 
memberdayakan warga negara melalui proses pendidikan agar dapat berpartisipasi aktif dalam sistem pemerintahan negara yang demokratis (Muchson, 2004:32). sehingga pada bagian berikutnya, artikel ini memaparkan implikasi kebijakan pendidikan yang berupa kajian pendidikan sebagaimana tampak dalam PP Nomor 57 Tahun 2021 tentang SNP.

\section{Jenis Penelitian}

\section{METODE PENELITIAN}

Penelitian ini menggunakan jenis penelitian studi literatur. Literatur review adalah penelitian yang dilakukan dengan membandingkan berbagai penelitian terdahulu kemudian dikaitkan dengan suatu topik penelitian yang dijadikan sebagai fokus review (Efron \& Ravid, 2019). Desain penelitian yang digunakan yaitu narrative review. Narrative review atau sering disebut dengan traditional literature review merupakan sebuah jenis literatur review dengan analisis dan sintesis secara menyeluruh untuk membangun sebuah teori dan konteks terhadap suatu fokus penelitian (Stratton, 2019).

\section{Prosedur Penelitian}

Kriteria artikel ilmiah yang digunakan sebagai data berupa artikel ilmiah bersumber dari jurnal, prosiding,dan repository dengan kemutakhiran 10 tahun terakhir yaitu dari tahun 2011-2020. Data artikel ilmiah yang digunakan minimal ada 10 artikel. Artikel ilmiah merupakan artikel yang dapat diakses secara terbuka oleh publik. Adapun langkah-langkah yang dilakukan dalam rangka pencarian artikel sebagai data penelitian literatur sebagai berikut:

1. Mengunjungi ke beberapa web berikut ini https://eric.ed.gov, https://www.doaj.org, http://garuda.ristekbrin.go.id, https://scholar.google.co.id.

2. Memasukkan kata kunci pencarian kebijakan, pendidikan, Pancasila dan PP Nomor 57 tahun 2021 pada kotak pencarian dari masing-masing web. Berdasarkan hasil penelusuran diperoleh jumlah artikel sesuai kata kunci melalui web https://eric.ed.gov sebanyak 1 artikel, web https://www.doaj.org sebanyak 7 artikel, web http://garuda.ristekbrin.go.id sebanyak 2 artikel, dan web https://scholar.google.co.id sebanyak 10 artikel. Secara keseluruhan jumlah artikel ilmiah berdasarkan penelusuran kata kunci sebanyak 20 artikel.

3. Tahap selanjutnya dilakukan filterisasi artikel ilmiah dengan cara mengeliminasi artikel ilmiah dengan gagasan topik yang sama jika ditemukan pada setiap sumber untuk meminimalkan kemungkinan gagasan topik penelitian yang rangkap, artikel ilmiah juga diseleksi berdasarkan tahun yaitu dari tahun 2011-2020. Data artikel ilmiah yang diperoleh pada tahap ini sebanyak 10 artikel ilmiah.

\section{Validasi/Review Kualitas Literatur}

Artikel ilmiah yang diperoleh berdasar kata kunci kebijakan, pendidikan, Pancasila dan PP Nomor 57 tahun 2021 sebanyak 15 artikel. Selanjutnya dilakukan review kualitas artikel ilmiah yang relevan dengan topik penelitian dengan cara membaca keseluruhan isi artikel ilmiah yang bertujuan melihat kesesuaian dengan topik penelitian diperoleh jumlah artikel sebanyak 10 artikel ilmiah yang relevan dengan topik penelitian.

Review kualitas literatur dilakukan dengan filterisasi artikel ilmiah yang akan digunakan untuk penelitian. Proses review kualitas literatur dilakukan dengan mempertimbangkan beberapa hal. Pertimbangan yang dijadikan sebagai dasar review kualitas literatur yaitu sumber pencarian artikel ilmiah yang terpercaya meliputi: 1) artikel ilmiah dapat diakses secara terbuka dan tidak berbayar melalui sumber web yang terpercaya; 2) kualitas metodologi penelitian yang digunakan pada artikel ilmiah termasuk dalam penelitian tindakan kelas dan quasi experiment; 3 ) kualitas penyajian 
data dan pembahasan; 4) kecukupan data yang relevan digunakan dalam analisis literatur; dan 5) referensi yang mutakhir tahun 2011-2020.

Data yang disajikan dalam penelitian diawali dengan pencarian artikel ilmiah yang relevan dengan kebijakan, pendidikan, Pancasila dan PP Nomor 57 tahun 2021. Daftar artikel ilmiah yang digunakan pada penelitian ini disajikan dalam bentuk tabel dengan format nomor, judul artikel, tahun peneliti, nama jurnal, dan link website. Teknik analisis literatur yang dilakukan pada penelitian ini adalah deskriptif. Pendekatan deskriptif dilakukan dengan cara mendeskripsikan temuan hasil analisis pada artikel ilmiah yang digunakan sebagai data penelitian, kemudian direpresentasikan dalam bentuk kalimat.Hal ini bertujuan agar dapat memberikan penjelasan lebih luas dan mendalam dari hasil analisis sehingga lebih mudah dipahami (Habsy, 2017).

\section{Hasil Penelitian}

\section{HASIL DAN PEMBAHASAN}

Dunia pendidikan terguncang akibat kebijakan yang dianggap tidak relevan. Kebijakan pemerintah dalam mengeluarkan Peraturan Pemerintah (PP) Nomor 57 Tahun 2021 tentang Standar Nasional Pendidikan (SNP) tertanggal 30 Maret 2021 menimbulkan kontroversi publik. Pasca keluarnya PP Nomor 57 tahun 2021 tentang SNP yang cepat beredar di masyarakat luas, telah menimbulkan pertanyaan berbagai kalangan dalam dunia pendidikan. Bagaimana mungkin namanya Pancasila dapat lenyap tanpa alasan rasional.

Keluarnya PP Nomor 57 tahun 2021 tentang SNP sebagaimana pada Pasal 40 ayat (3) telah menghilangkan keberadaan Pancasila (dan Bahasa Indonesia) dari kewajiban Kurikulum Pendidikan Tinggi tentu melukai hati kalangan pendidikan. Adanya bukti konsideran dalam PP Nomor 57 Tahun 2021 yang tidak merujuk prinsip lex specialissebagaimana Undang-Undang (UU) Nomor 12 tahun 2012 tentang Pendidikan Tinggi dalam Pasal 35 ayat (3) butir c yang jelas menyebut Kurikulum Pendidikan Tinggi wajib memuat Pancasila.

Tragisnya, Kemendikbud masih berdalih bahwa PP Nomor 57 tahun 2021 tentang SNP merupakan mandat dan turunan dari Undang-Undang Nomor 20 tahun 2003 tentang Sistem Pendidikan Nasional (UU Sisdiknas), sehingga ketentuan mengenai kurikulum pendidikan tinggi pada PP SNP hanya mengikuti UU Sisdiknas. Sebaliknya, secara hukumUndang-Undang Nomor 12 tahun 2012 tentang Pendidikan Tinggi tetap berlaku dan tidak bertentangan dengan UU Sisdiknas maupun PP SNP sendiri dan mata kuliah Pancasila tetap menjadi mata kuliah wajib pada jenjang pendidikan tinggi.

\section{Pembahasan}

Pandangan Carl J. Frederick tentang kebijakan negara sebagai "a proposed course a given environtment providing obstacles and opportunities which the policy was proposed to utilize and overcome in a effort to reach a goal or realize an objectives or a purpose"(Lester J.P, 1987. P. 21). Kebijakan Negara adalah sebagai rangkaian tindakan yang diusulkan oleh seseorang, sekelompok atau menunjukkan hambatanhambatan dan kesempatan-kesempatan terhadap pelaksanaan usulan kebijaksanaan tersebut dalam rangka mencapai tujuan tertentu.

Bahkan, pendapat James E. Anderson memberi gambaran kebijaksanaan sebagai "A purposive course of action followed by an actor or set of actors in dealing with a problems or matter of concern". (Kebijaksanaan sebagai rangkaian tindakan yang mempunyai tujuan tertentu yang diikuti dan dilaksanakan oleh seorang pelaku atau sekelompok pelaku guna memecahkan masalah tertentu) (Lester J.P, 1987. P. 21). Lebih lanjut Anderson mengemukakan "Public policy are those develop by government bodies and officials" (Kebijaksanaan negara adalah kebijaksanaankebijaksanaan yang dikembangkan oleh badan-badan dan pejabatan-pejabat pemerintah). 
Supaya kebijaksanaan Negara dapat memenuhi apa yang menjadi tuntutan (demand), kepentingan umum (pubic interest), dan pendapat umum (support), serta sumbersumber (resource) untuk menunjang tuntutan, maka kebijaksanaan Negara harus dibuat sebaik mungkin, dan perlu mendapat pengkajian yang cermat dan seksama, pada setiap tahapan dalam proses kebijaksanaan negara (public policy process). Jika menginginkan suatu kebijaksanaan dapat mencapai hasil seperti yang diharapkan, maka dituntut dengan suatu rencana yang baik dan diikuti dengan implementasi kebijakan yang baik pula. (Hasan Suryono: 2016. Hal. 86)

Usaha pemerintah untuk mengatasi persoalan-persoalan pendidikan sebagai bagian dari usaha dan solusi yang relevan dengan situasi kesenjangan pendidikan saat ini merupakan langkah yang perlu dicermati. Barangkali pemegang kebijakan lupa bila pendidikan nasional suatu bangsa menjadi satu unsur pemersatu, pengikat, penumbuh dan pengarah cita-cita nasional. Kesalahan saat menempatkan kebijakan pendidikan mengakibatkan goncangan yang rentan mengoyak kebhinekaan.

Kebijakan penghapusan Pancasila sebagaimana PP Nomor 57 tahun 2021 tentang SNP terasa kurang bijaksana. Kemendikbud "kecolongan" karena tidak memasukkan secara eksplisit mata pelajaran Pancasila sebagai pelajaran wajib. Hal ini membuat masyarakat memanas karena pada PP Nomor 57 tahun 2021 tentang SNP memang tidak disebutkan mengenai Pancasila.Artinya, bahwa kebijakan Pancasila dalam PP Nomor 57 tahun 2021 tentang SNP harus mempertimbangan beberapa aspek yang terkait.

\section{A. Aspek regulasi sebelumnya.}

Pertimbangan merumuskan PP Nomor 57 Tahun 2021 tentang SNP semestinya harus melihat regulasi sebelumnya yang menjadi dasar utama penjabaran atau perubahan aturan. Adapun regulasi sebelum yang seharusnya menjadi dasar PP Nomor 57 Tahun 2021 tentang SNP sebagai berikut. Pertama, Amandemen UndangUndang Dasar (UUD) 1945. Dalam amandemen UUD 1945 telah menegaskan, terutama pada Bab XIII tentang Pendidikan dan Kebudayaan sebagaimana bunyi Pasal 31 ayat (3) bahwa pemerintahmengusahakan dan menyelenggarakan satu sistem pendidikan nasional, yang meningkatkan keimanan dan ketakwaan serta ahlak mulia dalam rangka mencerdaskan kehidupan bangsa, yang diatur dengan undangundang.

Kedua, Undang-Undang Nomor 20 tahun 2003 tentang Sistem Pendidikan Nasional (Sisdiknas) yang tentu tidak boleh dilihat hanya sepotong-sepotong. Karena dalamnya dijelaskan pada pasal 38 ayat (3) bahwa kurikulum pendidikan tinggi dikembangkan perguruan tinggi yang bersangkutan dengan mengacu kepada standar nasional pendidikan untuk setiap program studi. Begitu pula ayat (4) bahwa kerangka dasar dan struktur kurikulum pendidikan tinggi dikembangkan oleh perguruan tinggi yang bersangkutan dengan mengacu pada standar nasional pendidikan untuk setiap program studi. Artinya bahwa standar nasional pendidikan tidak boleh dimaknai secara dangkal, tetapi perlu detail dan mendalam dengan mempertimbangan aspek regulasi yang lain.

Ketiga, sangat jelas dan tertuang pada Undang-Undang Nomor 12 Tahun 2012 tentang Pendidikan Tinggi sebagaimana Pasal 35 ayat (3) bahwa kurikulum pendidikan tinggi sebagaimana dimaksud ayat (1) wajib memuat mata kuliah: a. agama; b; Pancasila; c. Kewargaraan; dan d. bahasa Indonesia. Sehingga memang UU Nomor 12 tahun 2012 tidak bertentangan dengan UU Sisdiknas dan linier dengan PP SNP sendiri sekaligus mata kuliah Pancasila tetap menjadi mata kuliah wajib pada jenjang pendidikan tinggi dengan disertai sisi regulasi.

Keempat, sebelum lahirnya PP Nomor 57 tahun 2021, ada PP Nomor 13 tahun 2015 tentang Perubahan Kedua Atas Peraturan Pemerintah Nomor 19 tahun 2005 tentang Standar Nasional Pendidikan sebagaimana Pasal 17 ayat (4) bahwa kurikulum tingkat satuan pendidikan untuk setiap program studi di perguruan tinggi 
dikembangkan dan ditetapkan oleh masing-masing perguruan tinggi dengan mengacu Standar Nasional Pendidikan. Terbitnya PP 57 tahun 2021 semestinya melengkapi aturan sebelumnya yang tidak ada.

Dengan pengaturan kurikulum wajib pendidikan tinggi yang telah diatur dalam Undang-undang Nomor 12 tahun 2012 tentang Pendidikan Tinggi perlu dipertegas. Keberadaan Pancasila wajib dalam kurikulum demi mencegah kesalahpahaman lebih jauh. Bukan hal tabu bila Pemerintah bersedia membatalkan PP Nomor 57 Tahun 2021 tentang SNP atau merevisi Pasal 40 yang memuat substansi kurikulum wajib berbagai jenjang pendidikan.

Kelima, adanya Keputusan Direktorat Jenderal (Dirjen) Pendidikan Tinggi Nomor 84/E/KPT/2020 tentang Pelaksanaan Pedoman Mata Kuliah Wajib Pada Pendidikan Tinggi. Keberadaan PP Nomor 57 Tahun 2021 tentang SNP harus memperhatikan Keputusan Dirjen Pendidikan Tinggi tersebut karena sudah mengatur sebelumnya. Jangan sampai ada timpang tindih atas keberadaan PP Nomor 57 Tahun 2021 tentang SNP terhadap regulasi yang telah ada.

Keenam, Peraturan Presiden Republik Indonesia nomor 8 tahun 2012 tentang Kerangka Kualifikasi Nasional Indonesia (KKNI). Pengembangan kurikulum pendidikan tinggi, khususnya mata kuliah pendidikan Pancasila harus sesuai dengan visi misi institusi pada setiap program studi. Dalam konteks ini, PP Nomor 57 Tahun 2021 tentang SNP harus direvisi karena yang akan direkonstruksi kurikulum mata kuliah pendidikan Pancasila, maka pengembangan kurikulumnya harus disesuaikan dengan visi, misi dan tujuan dari program studi.

Ditetapkannya Peraturan Presiden Republik Indonesia nomor 8 tahun 2012 tentang Kerangka Kualifikasi Nasional Indonesia (KKNI) kurikulum tentu harus merujuk pada cakupan capaian pembelajaran. Dengan demikian mata kuliah pendidikan Pancasila yang sifatnya mata kuliah umum dan wajib bagi program sarjana dan diploma tentunya harus ada keseragaman capaian pembelajaran untuk semua mahasiswa dari berbagai jurusan dan program studi pendidikan. Keberadaan PP Nomor 57 Tahun 2021 tentang SNP semestinya merujuk Peraturan Presiden Republik Indonesia nomor 8 tahun 2012 tentang Kerangka Kualifikasi Nasional Indonesia (KKNI).

\section{B. Aspek Politik Pendidikan.}

Proses mengeluarkan kebijakan apapun tentu tidak lepas dari berbagai kepentingan politik, termasuk perumusan PP Nomor 57 Tahun 2021 tentang SNP. Karena yang namanya reformasi pendidikan pasti akan melibatkan banyak elemen baik di tingkat suprastruktur maupun infrastruktur, yang tujuan utamanya ialah terjadi perubahan dan pembaharuan di bidang pendidikan. Keluarnya kebijakan PP Nomor 57 Tahun 2021 tentang SNP tentu tidak lepas dari kepentingan politik pendidikan dibaliknya.

Dalam pandangan kalangan sarjana politik pendidikan dikenal dengan dua kelompok aliran (Wong,1995:24-25) yang getol mengajukan konseptualisasi struktur kekuasaan dan praktik demokrasi. Pertama, adalah kelompok "elitis" yang mengajukan kerangka untuk memusatkan kepada bagaimana komunitas ekonomi dan elite politik secara erat mendominasi pembuatan kebijakan pendidikan. Kedua, kelompok "pluralis", dimana perspektifnya memfokuskan kepada kebijakan-kebijakan pendidikan yang dipengaruhi oleh persaingan kepentingan, perselisihan partisan, dan pemilihan terbatas.

Sejalan dengan teorisasi Easton (1966: 339) terhadap kajian sistem politik dengan menganalisis bagaimana keputusan-keputusan otoritatif dibuat, analisis kebijakan politik pendidikan akan terkait erat dengan proses-proses pembuatan keputusan politik (kebijakan pendidikan). Dalam proses pembuatan keputusan itulah kerja mekanisme politik (input-proses-output) amat menentukan akomodasi dan agregasi nilai-nilai yang diperjuangkan pemerintah, kelompok kepentingan, dan 
organisasi masyarakat lainnya. Proses akomodasi dan agregasi kepentingan memerlukan berbagai perundingan.

Pandangan Archer (1985:42-47) mengelompokkan tipe negosiasi dalam analisis politik pendidikan, yakni tipe "internal initiation," tipe "external transaction," dan tipe "political manipulation." Di tipe inisiasi internal, upaya perubahan kebijakan pendidikan datang dari kalangan profesi pendidikan, seperti halnya organisasi guru atau kelompok sarjana pendidikan yang relevan. Untuk tujuan inisiatif juga dapat beragam, namun akan selalu tergantung kepada profesi yang diperolehnya dan hakhak legal untuk mewujudkannya dalam kenyataan sehari-hari. Pada inisiasi internal perlu melakukan pertukaran sumber daya dengan kelompok-kelompok kepentingan eksternal.

Sedangkan, pada tipe transaksi eksternal, negosiasi oleh kelompok internal pendidikan akan melibatkan kelompok kepentingan eksternal. Sebaliknya, khusus tipe manipulasi politik, proses negosiasi dimaksudkan untuk mempengaruhi antara pemerintah dan kelompok profesi di satu pihak, dan tipe pertama dengan tipe ketiga. Di pihak lain juga sekaligus guna memberikan penolakan atau dukungan terhadap alokasi nilai-nilai yang akan diperjuangkan sebagai kebijakan publik.

Ironisnya, perumusan PP Nomor 57 Tahun 2021 tentang SNP barangkali tidak melalui proses politik yang terbuka. Sehingga pada saat ada celah kurang atas perumusan PP Nomor 57 Tahun 2021 tentang SNP, maka kepentingan lain yang terganggu akan bereaksi secara cepat dalam merespon penolakan kebijakan yang ada. Bahkan, publik akan menolak atau menegosiasikan kepentingannya supaya masuk kedalam pusaran kebijakan yang menguntungkan kepentingannya.

\section{Aspek Reformulasi Pendidikan}

Pendidikan Pancasila merupakan salah satu mata pelajaran yang sangat penting bagi kebanyakan negara dibelahan dunia. Mata pelajaran ini di dalamnya mengandung beberapa muatan politik negara yang diarahkan pada peningkatan rasa nasionalisme dari masing-masing negara. Pendidikan Pancasila pada dasarnya bermuara pada demokrasi politik.Pada konteks persekolahan, pendidikan Pancasila memiliki kewajiban utama yaitu menjadikan peserta didik sebagai warga negara yang baik dan cerdas (smart and good citizens). Warga negara yang baik merupakan warga negara yang memiliki pemahaman dan kesadaran tentang hak dan kewajibannya sebagai warga negara Indonesia.

Pada konteks modern, nasionalisme lebih diarahkan pada konsep kesetiaan tertinggi kepada bangsa dan negara. Negara Indonesia sebagai salah satu nation-state telah mengalami beberapa tahap proses perkembangan nasionalisme. Berdasarkan hal tersebut, menjadi penting adanya reformulasi pendidikan Pancasila dalam rangka meningkatkan nilai-nilai nasionalisme. Sebagaimana pendapat Banks (2008:135) yang menyatakan perlunya konsepsi ulang Pendidikan Pancasila pada abad 21 agar mampu secara efektif mendidik peserta didik untuk menjadi warga negara yang memiliki fungsi. Sehingga terminologi pendidikan Pancasila harus dimaknai dalam konsep yang luas untuk menghadapi tantangan global (Setiarsih, 2017: 80). Reformulasi pendidikan akan menuai keberhasilan ketika mendasarkan pengetahuan transformatif dari pengetahuan yang mainstream. Reformulasi yang dimaksudkan mengarahkan Pendidikan Pancasila menjadi salah satu mata pelajaran yang mampu menjadikan peserta didik memiliki apa yang disebut sebagai "Act locally and think globally" yang dimaknai mempertahankan nilai-nilai, budaya, adat asli Indonesia, akan tetapi memiliki cara pandang yang tidak ketinggalan dari kancah internasional.

Kebijakan PP Nomor 57 Tahun 2021 tentang SNP harus dimaknai secara luas secara filosofis dan ideologis. Pendidikan Pancasila sebagai salah satu pendidikan politik, pendidikan demokrasi, dan pendidikan moral dalam lingkup persekolahan, harus mampu memberikan pemahaman yang utuh tentang makna melestarikan nilainilai kebangsaan yang berpangkal pada kualitas ke-Indonesiaan. 
Dari berbagai aspek yang ada, kiranya pemerintah harus bersedia menerima masukan dalam proses revisi PP Nomor 57 Tahun 2021 tentang SNP. Kemendikbud tidak perlu terlalu terburu-buru melakukan usulan revisi yang hanya fokus pada satu persoalan pendidikan, tetapi harus melihat secara komprehensif terhadap seluruh persoalan pendidikan Pancasila. Tujuan revisi PP Nomor 57 Tahun 2021 tentang SNP harusnya tidak hanya karena desakan dan penolakan publik, tetapi bagaimana strategi mengatur dan memperkuat implementasi terhadap kurikulum Pancasila dan pengamalan nilai-nilai Pancasila dalam dunia Pendidikan. .

\section{SIMPULAN}

Kebijakan pendidikan Pancasila dalam Peraturan Pemerintah Nomor 57 Tahun 2021 tentang Standar Nasional Pendidikan (SNP) harus direvisi. Pancasila harus menjadi muatan wajib di dalam sistem pendidikan Indonesia. Apalagi tujuan program Merdeka Belajar yaitu profil pelajar Pancasila sebagai transformasi pendidikan. Pengenalan Pancasila dalam pemahaman dan aplikasi Pancasila menjadi pilar utama daripada transformasi pendidikan Indonesia.

Kebijakan pendidikan Pancasila di Indonesia pada era reformasi melalui revisi PP Nomor 57 Tahun 2021 tentang SNP tidak dapat dilepaskan dari politik nasional yang melatarbelakanginya. Reformasi di segala aspek kehidupan berbangsa dan bernegara melalui revisi PP Nomor 57 Tahun 2021 tentang SNP, pada gilirannya membawa perubahan pada aspek paradigmatik kajian dan pembelajaran pendidikan Pancasila di Indonesia dari aspek standardisasi pendidikan.

Langkah revisi PP Nomor 57 Tahun 2021 tentang SNP butuh pemantapan kedudukan Pendidikan Pancasila sebagai mata pelajaran wajib untuk pengembangan kepribadian (sebagai warga negara yang baik). bahkan, pada sisi lain berharap para pengembang pendidikan Pancasila agar di masa depan dalam pengembangan substansi kajiannya tidak tergantung kepada pergantian rezim kekuasaan.

\section{DAFTAR PUSTAKA}

Anderson, James E. 1979. Public Policy Making. New York: Holt, Praeger.

Archer, M. S. 1985. "Educational Politics: A Model for Their Analysis." in: Ian McNay and Jenny Ozga. (eds.). Policy-Making in Education. Oxford: Pergamon Press and The Open University.

Banks, J.A. (2008). Diversity, Group Identity, and Citizenship Education in a Global Age. Educational Researcher, 37 (3), 129-139.

Easton, D. 1966. "An Approach to the Analysis of Political Systems," in: Milton L. Barron (ed.), Contemporary Sociology: An Introduction Text book of Readings. New York and Toronto: Dodd, Mead \& Company

Hassan Suryono. (2016). Kebijakan Hukum Penataan Kurikulum Mata Kuliah Kewarganegaraan di Perguruan Tinggi Guna Revolusi Karakter Mentaati Hukum Bagi Mahasiswa. Jurnal IImiah Pendidikan Pancasila dan Kewarganegaraan, Th. 1, Nomor 2, Desember 2016

Lester, James P. dan Joseph Stewart Jr. 2000. Public Policy: An Evolutionary Approach (second edition). Australia: Wadsworth Thomson Learning.

Muchson, 2004. "Pendidikan Kewarganegaraan Paradigma Baru dan Implementasinya dalam Kurikulum Berbasis Kompetensi”. Jurnal Civics, 1(1), 29-41.

Samsuri. (2011).Kebijakan Pendidikan Kewarganegaraan Era Reformasi di Indonesia. Cakrawala Pendidikan, Juni 2011, Th. XXX, No. 2. Universitas Negeri Yogyakarta. Yogyakarta

Sutiyono, Suharno. (2018). Reformulasi Pendidikan Pancasila dan Kewarganegaraan untuk menguatkan Nasionalisme Warga Negara Muda di Wilayah Perbatasan. 
Citizenship Jurnal Pancasila dan Kewarganegaraan Vol 6 No 1 April 2018, hal 116. http://e-journal.unipma.ac.id/index.php/citizenship

Wong, K. J. 1995. "The Politics of Education: From Political Science to Interdisciplinary Inquiry". in: Jay D. Scribner dan Donald H. Layton (eds.). The Study of Educational Politics. Washington D.C, dan London: The Falmer Press.

Keputusan Direktorat Jenderal Pendidikan Tinggi Nomor 84/E/KPT/2020 tentang Pelaksanaan Pedoman Mata Kuliah Wajib Pada Pendidikan Tinggi.

Peraturan Pemerintah Republik Indonesia Nomor 13 tahun 2015 tentang Perubahan Kedua Atas Peraturan Pemerintah Nomor 19 tahun 2005 tentang Standar Nasional Pendidikan

Peraturan Pemerintah Republik Indonesia Nomor 57 Tahun 2021 tentang Standar Nasional Pendidikan

Peraturan Presiden Republik Indonesia nomor 8 tahun 2012 tentang Kerangka Kualifikasi Nasional Indonesia (KKNI)

Undang-Undang Dasar Tahun 1945

Undang-Undang Nomor 20 Tahun 2003 tentang Sistem Pendidikan Nasional.

Undang-Undang Nomor 12 Tahun 2012 tentang Pendidikan Tinggi. 